Revue de l'Institut des langues et cultures

d'Europe, Amérique, Afrique, Asie et Australie

$44 \mid 2021$

Peinture, identité nationale et style international en

Europe autour de 1900

\title{
Sorolla, la construcción de un nuevo canon y la exposición como estrategia de legitimación
}

Sorolla, the Making of a New Canon and Exhibitions as a Legitimising Strategy

Isabel Tejeda Martín

\section{OpenEdition}

\section{Journals}

Edición electrónica

URL: https://journals.openedition.org/ilcea/12569

DOI: $10.4000 /$ ilcea.12569

ISSN: 2101-0609

Editor

UGA Éditions/Université Grenoble Alpes

Edición impresa

ISBN: 978-2-37747-324-3

ISSN: $1639-6073$

Referencia electrónica

Isabel Tejeda Martín, «Sorolla, la construcción de un nuevo canon y la exposición como estrategia de legitimación», ILCEA [En línea], 44 | 2021, Publicado el 02 noviembre 2021, consultado el 03 diciembre 2021. URL: http://journals.openedition.org/ilcea/12569 ; DOI: https://doi.org/10.4000/ilcea. 12569

Este documento fue generado automáticamente el 3 diciembre 2021.

(C) ILCEA 


\section{Sorolla, la construcción de un nuevo canon y la exposición como estrategia de legitimación}

Sorolla, the Making of a New Canon and Exhibitions as a Legitimising Strategy

Isabel Tejeda Martín

1 Joaquín Sorolla disfrutó de una exitosa carrera tanto nacional como internacional durante su vida, participando en exposiciones y certámenes importantes en París, Berlín, Viena, Londres, Múnich y Nueva York, lo que le convirtió en la imagen internacional de una renovada pintura española a principios de la centuria. Si en París se produce su consagración europea al ganar consecutivamente relevantes premios en sus salones desde finales del 800, en Nueva York la exposición de 1909 en la Hispanic Society gozó de una audiencia inusitada con largas colas bajo la nieve; de hecho, esta muestra es uno de los primeros fenómenos sociales de carácter expositivo del siglo XX que merece un estudio per se. Y es que el otro lado del Atlántico estaba ganando peso específico en la consagración de los artistas más significativos del mundo, un proceso paulatino que alcanzaría su máxima expresión tras la Segunda Guerra Mundial (Guilbaut, 2007). El éxito norteamericano de Sorolla emulaba el que habían disfrutado los impresionistas franceses allí gracias a la aparición de un nuevo mercado para el arte del momento, que sustituía a la academia en la legitimación del canon artístico; de extracción familiar muy modesta, Sorolla falleció de hecho millonario en 1923. Al triunfo internacional se unía en España el entusiasmo popular por su pintura y persona, basta ver las imágenes de la prensa que muestran su féretro escoltado en Valencia por una gran muchedumbre.

¿Qué ocurrió para que su notoriedad se desinflara tras su muerte? Su presencia en la historiografía del arte español se vio amortiguada por la polémica enconada entre dos presuntos discursos pictóricos e iconográficos antagónicos. La pintura de Sorolla, que experimentó su clímax durante lo que Pío Baroja llamó las «grandes discusiones entre casticistas y modernistas» (2012: 10), sufrió el escarnio directo de los diferentes argumentos que atravesaban la "crisis de conciencia» de la intelectualidad española 
tras la pérdida de las últimas colonias a finales del ochocientos (Álvarez Junco, 2001: 586)1. Más tarde, la pujante emergencia de unas vanguardias que transformaron de forma radical la pintura con su arrolladora modernidad desde las grandes metrópolis del mundo, eclipsó la pintura que en su momento había supuesto una bocanada de aire fresco en la circunspecta pintura de historia del xIx; Sorolla carecía de la radicalidad presente por ejemplo en la obra de Pablo Picasso y de los artistas de su generación afincados en París, una generación que, como reflexiona Jesusa Vega, provocó que las obras innovadoras propuestas a finales de siglo «parecieran tradicionales, incluso pasadas de moda» (2018: 529)². Este rotundo cambio de canon artístico indujo a que el escenario internacional olvidara a Sorolla en poco tiempo, perdiendo su posición privilegiada entre la nómina de autores españoles de su generación.

\section{España Negra vs España Blanca}

3 Existía en aquellos momentos una pugna ideológica, sin base empírica, entre los que consideraban que la solución a la «decadencia española» estaba en buscar las raíces creativas, lo auténtico, en el pasado histórico español o en su paisaje (Ladero Quesada, 1996: 27), y los partidarios del cosmopolitismo que argumentaban que era preciso salir del aislamiento y mirar hacia afuera (premisa que empujó a nuestros artistas más emergentes a «huir» de nuestras adocenadas escuelas de bellas artes para buscar fortuna creativa y comercial fuera de España). Paradójicamente, Sorolla encontró detractores en ambas opciones, siendo chocante que sus adeptos esgrimieran argumentos similares para reivindicar su memoria o sus contrarios para tumbarla.

4 La polémica respecto a la obra de Sorolla tiene su origen por tanto en sus compatriotas contemporáneos. La posición nacionalista acentuaba bien nuestra historia como modelo de glorias pasadas, bien el paisaje como conformador de identidades comunes. Liderada por los intelectuales de la Generación del 98, su discurso consideraba que la pintura colorista y luminosa de Sorolla, su joie de vivre, no se ajustaba a su idea del espíritu e identidad españoles (Garín \& Tomás, 2009: 473). El pintor, que pasó gran parte de su vida cerca de la corte madrileña y tuvo contactos con una significativa pléyade de intelectuales del momento, no contó siempre con su beneplácito, si bien su cercanía a la Institución Libre de Enseñanza generó cuantiosos apoyos de este bando (Hernández, 2014). La historiografía de Sorolla cuenta con los análisis y comentarios de Ortega y Gasset, Valle-Inclán, Unamuno, Azorín o Pío Baroja, entre otros. Empero, es importante entender que estos pensadores no eran historiadores del arte sino que, de forma un tanto apriorística y con reflexiones plagadas de tópicos e intuiciones, robustecían un constructo nacional, el de una identidad española común rastreable en el tiempo, una identidad, un pretendido «temperamento nacional» (Portús, 2012: 211) que para ellos tenía su expresión fundamental en la literatura o el arte (Ladero Quesada, 1996: 34). Autores que militaban en su mayoría en el regeneracionismo o que, pertenecientes a la Generación del 98, utilizaban Castilla como metonimia de España y la filiación del Estado Imperial, quedando fuera de su interés y beneplácito otras singularidades locales o sensibilidades ajenas al tópico de la España profunda, austera, y católica (representada por Zuloaga). Esto situaba a Sorolla en una tierra de nadie al verse ligado a otro constructo que aún pervive adherido a su obra: una manera levantina de ver y vivir la existencia, más sensual, y según algunos de estos 
intelectuales, frívola (Llorens, 2016). Este pensamiento se convirtió en hegemónico filtrándose a la crítica profesional y a su consideración historiográfica ${ }^{3}$.

Para estos escritores la pintura de Sorolla era superficial. Cuando Unamuno en 1912 conecta religiosidad y realismo en su «estética de la salvación del individuo», deja fuera la obra de Sorolla, excesivamente carnal y pagana (Portús, 2012: 218). Valle Inclán, por su parte, contraponía en 1919 la hipotética escuela levantina a la expresión castellana en una lectura maniquea: lo levantino era falso, carente de conciencia, pura imitación alejada de «la belleza superior de las cosas» (Garín \& Tomás, 2009: 473). Por su parte, José Ortega y Gasset en 1925 identifica la sensualidad que emana del pintor valenciano con una cultura mediterránea nada mística y por tanto poco profunda (Garín \& Tomás, 2009: 473). Reflexiones que han envejecido mal al pertenecer al ámbito de la ideología, e incluso de las opiniones personales o de la historia del gusto.

Las adscripciones de esta pintura a distintos movimientos pictóricos también jugaron a veces en su contra. Para sus contemporáneos Sorolla fue un pintor naturalista, algo que él compartía. Pero también se le ha catalogado de impresionista. Recordemos que a finales del xIx la pintura naturalista de escenas cotidianas supuso una ruptura frente a la tendencia académica que había marcado el siglo: la pintura de historia. Al mismo tiempo, el naturalismo se anclaba en la tradición identificándose, tras la transformación general del gusto que escoró el clasicismo dieciochesco, con la idea de Escuela Española (Géal, 1999), un constructo plagado de tópicos que pretendía «identificar rasgos nacionales en una disciplina artística que si por algo se ha distinguido durante la Edad Moderna ha sido precisamente por el carácter internacional de sus lenguajes» (Portús, 2012: 171); esta noción concebía el carácter español como una personalidad colectiva resistente a las influencias foráneas y unida por rasgos biológicos idénticos, algo que leemos como una patología nacionalista tras un siglo xIX traumático, debido a la merma del peso específico internacional de España. El naturalismo de Sorolla permitía a estos nacionalistas estéticos conectar su pintura con la tradición autóctona, siendo constantes las referencias a Velázquez, convertido «en el paradigma de artista español» (Portús, 2012: 176). Poco importaba la realidad: el pintor valenciano no sólo no se resistió a las influencias de distintos artistas europeos, sino que transformó su forma de pintar tras sus numerosas estancias en el extranjero.

7 Aureliano de Beruete se alineaba con esta adscripción al calificar a Sorolla de naturalista, subrayando las influencias del Bastien-Lepage o Zorn (De Beruete, 1901: 200). Sin embargo, en una revisión del texto que publicó en 1921, hace especial referencia a los impresionistas en unas páginas añadidas (24 a 29), subrayando que Sorolla conocía la obra de los impresionistas bajo cuyo influjo dejó de utilizar los negros $\mathrm{y}$ tonos pardos cuando pintaba à plein air:

No menor interés ofrece la manera con la cual interpreta la vibración de la luz, especialmente aquella que produce el sol al iluminar directamente los objetos. Para dar idea de estos efectos, recurre a veces al uso de pinceladas menudas de gran acento y vibración, sin caer en las exageraciones de muchos pintores modernos de los llamados impresionistas, por aplicar igualmente la pincelada pequeña todos los efectos, lo mismo a los de aire libre que los de interior, y aún a los retratos pintados a la luz de un estudio.

Sorolla vio pronto y con gran sagacidad lo que hay de bueno y verdadero en el impresionismo y en las fases diversas que representa, y se lo asimiló inmediatamente. Así vemos proscritos de su paleta, para los cuadros pintados al aire libre, los colores pardos y negros, poco transparentes, que hasta hace no mucho fueron los preferidos por los pintores para las sombras. Ofrecen en cambio, 
sus lienzos una gran variedad de tintas azules y violetas, contrapuestas a las amarillas y rojas, con las cuales y con el uso discreto el blanco, obtiene acordes riquísimos y efectos de color muy brillantes y atrevidos. (De Beruete, 1921: 28-29) siempre el fuste de su mirada), los resultados de su pintura no pueden tildarse literalmente de realistas o naturalistas: hay pinturas bañadas en una idealización de lo visible que reverbera y exagera el color y la luz hasta el paroxismo, una hiperbolización originada en las emociones que sentía el pintor al plasmar lo que estaba viendo, y para la que se servía más de la intuición que de recetas. En su personal fuga del concepto de mímesis, en ocasiones experimenta con la independencia del color respecto a lo real, al tiempo que genera unas composiciones cuidadosamente diseñadas que, casi a modo de collage, iban más allá de lo que el pintor veía (los paneles de la Hispanic Society son construcciones). El sueño positivista de alcanzar la objetividad que impregnara el naturalismo tanto literario como pictórico era un imposible: no lo conseguía la fotografía (de la que él un auténtico valedor, influyendo poderosamente en su trabajo) ni, por supuesto, la pintura. No podemos entender la obra de Sorolla desde un punto de vista positivista o, en otro contexto, como hija de un presunto cientifismo de la pincelada que ha podido defenderse en algunos impresionistas: no hace falta entender el agua para zambullirse en ella.

El problema de la adscripción aumenta porque no hay un solo Sorolla. Si en su etapa de pintura social detalla escenas que ha visto, y se convierte en un notario crítico de En este sentido Sorolla es un pintor moderno: no lleva a cabo una transposición mimética de la realidad al lienzo sino pintura pura y simple, y es muy consciente. Lo hace sirviéndose del color desde un punto de vista expresivo y autónomo. La emoción, casi en sentido romántico, es el puente entre la mirada y su mano, surgiendo tanto de lo que observaba como del instante de la producción. Esta apreciación lleva a las reflexiones de Jonathan Crary en su concepción de la modernidad: la superación de la visión clásica aporta una percepción formada como experiencia temporal que funde lo visto con las sensaciones y emociones nacidas de los estímulos visuales; aquéllas convierten al artífice en tamiz, lo que denomina densidad carnal de la visión, reubicando por empatía al espectador (Crary, 2008: 194).

\section{El canon modernista y Sorolla}

11 Los discursos de la intelectualidad española de entre siglos se cruzaron con la construcción de un canon modernista que obviaba muchas corrientes de la pintura nacidas en el siglo xIX sin darles sentido genealógico de continuidad. Este canon situaba de nuevo a Sorolla en otro callejón sin salida: el autor que había supuesto un soplo de aire fresco frente a la pintura de historia, poco después se convertía en el cabo muerto 
de la tradición en un constructo que lo oponía a la vanguardia; ésta había irrumpido en tromba como sinónimo de lo nuevo, experimental, original, provocador y antiacadémico. La idea de progreso atravesaba esta exitosa corriente apuntalada por el diagrama del torpedo de Alfred Barr proyectado en 1936 desde el MoMA (Kantor, 2001: 366); figuras nacidas después del pintor valenciano -como Picasso- se convertían en los nuevos faros sobre los que construir el camino de la creación y experimentación plástica. El naturalismo quedaba relegado a entenderse como un estilo figurativo y mimético, el último coletazo de la tradición clásica, mientras que el impresionismo y sus secuelas sentaban los cimientos de la modernidad. En España podemos leer la situación si atendemos a la primera alternativa renovadora relevante respecto al arte oficial: la Exposición de la Sociedad de Artistas Ibéricos; este proyecto concitó el interés de los medios y del público, propugnando un anti-aislacionismo que conectara a España con el resto de Europa. En una carta que Salvador Dalí, presente en dicha exposición, escribía a Francisco Bores, le apremiaba a firmar un manifiesto conjunto que declarara su rechazo a la pintura oficial y a la «horrible pintura valenciana» que había falsificado el impresionismo francés «a través de la incomprensión de los pintores valencianos que, como Muñoz Degrain, causan asombro en la Academia, y que según nosotros, después de Sorolla pocos pintores han hecho tanto daño a la juventud». Tras tan seria acusación, Dalí incluía una retahíla de nombres a seguir por su generación: Derain, Picasso, Matisse, Gris, Picabia o Chirico, entre otros. (Pérez Segura, 1997: 360)

Este canon modernista que excluía fórmulas ajenas a las vanguardias europeas, fue aceptado mayoritariamente en los ámbitos académicos, museísticos, y en el mercado. Los artistas que habían triunfado en un sistema de las artes en crisis por haber seguido discursos alternativos a las vanguardias - nueva academia e insólito canon-, quedaban en el pasado caduco o en tierra de nadie, alimentándose una lectura acomplejada de lo propio que no siempre tuvo justificación, pero que se fue generalizando. Arrinconados, fueron olvidados, perdurando su memoria exclusivamente en sus ámbitos locales.

Muchos de los artistas y teóricos de las siguientes generaciones estarán impregnados de antisorollismo. A este hecho se suma el despertar del compromiso político en la Europa de entreguerras que en España se agudizó durante la II República y la Guerra Civil. La reivindicación de un arte con mensaje político y capacidad de transformación social se presentaba como una alternativa a la propuesta experimental y metalingüística de una gran parte de artistas de la modernidad; de nuevo Sorolla quedaba fuera de juego. En Valencia el caso paradigmático fue Josep Renau: se declaró en contra de Sorolla en 1929 en el «Manifiesto contra la exposición de arte de Levante» (García: 2014).

\section{La fortuna crítica de Sorolla durante el franquismo}

Durante el franquismo el pensamiento noventayochista continuó siendo hegemónico, cruzándose desde la agazapada izquierda artística e intelectual con la absorción del canon internacional de la modernidad. Llovía sobre mojado al mantenerse la condena unánime a la pintura de Sorolla (Garín \& Tomás, 2009: 482). Un par de instituciones, sin embargo, se resistieron a la tendencia general: la Casa Museo Sorolla y la Academia de San Carlos de Valencia; en esta última se generó un grupo de seguidores que se denominó escuela sorollista ${ }^{4}$. La existencia de estos discípulos no redundó en favor de la consideración del pintor, más bien al contrario, ya que las fórmulas gramaticales e iconográficas de Sorolla, esa manera tan intuitiva de pintar, se habían convertido en 
una receta repetida machaconamente en todas las asignaturas de pintura de la escuela. A eso se suma una academia que en la dictadura estaba desconectada de la realidad artística, lo que produjo un gran rechazo en las jóvenes generaciones de artistas locales formados entre 1950 y 1980. Entre ambas posturas, la voz siempre independiente de Gaya Nuño analizaba el negativo impacto de los sorollistas:

Algo hay que ha empañado esa fama póstuma, y ha sido el sorollismo y, esto es, la indiscreta y profusa floración de pintores, valencianos los más de ellos, que sin poseer ni de lejos las dotes del maestro se afanaban en imitar su técnica, su temática, todo lo que le había conducido al éxito. Por descontado, este sorollismo multitudinario no debe afectar para nada el prestigio de su involuntario creador, pero, a merced de mecanismos mentales de mal funcionamiento, sí ha contribuido a disminuirlo. Naturalmente, no se dan aquí los nombres de los integrantes de modalidad tan falsa y gregaria (1958: 94).

También el gran público, sobre todo en Valencia, preservaba indeleble su admiración ante su hito local. Al tratarse de una pintura fácilmente comprensible, iconográficamente amable y muy agradable de ver, la dictadura aprovechó esta devoción popular para ilustrar sellos, postales, tapices, e incluso billetes de curso legal. Así Sorolla era reconstruido en un nuevo imaginario al servicio propagandístico de la dictadura.

La dictadura propicia los primeros intentos, si bien tímidos, de rehabilitación de la figura de Sorolla. El primer evento fue la exposición-homenaje que le rindió su yerno, el pintor sorollista Francisco Pons Arnau, en 1944, en los bajos de las Casas Consistoriales de Valencia con obras de la colección familiar; contó según la prensa con 100000 visitantes y la asistencia del director General de Bellas Artes. El segundo coincidió con el centenario del nacimiento (1963), una muestra antológica en el Casón del Buen Retiro de relevancia para el régimen pues fue inaugurada por el propio Franco; reunió 132 pinturas y 26 bocetos. Gratiniano Nieto, director General de Bellas Artes, justificaba la exposición porque el Estado se sentía en deuda con Sorolla, pintor poseedor de «una fervorosa pasión hispánica» que disfrutó un gran éxito en vida, que donó parte de su colección y la casa familiar: el Museo Sorolla, inaugurado en 1932 (Nieto, 1963). Por su parte Bernardino de Pantorba conectaba la obra de Sorolla con el impresionismo por su plenairismo, los temas cotidianos y el tratamiento de la luz, e iba más allá al considerarla una pintura independiente que no partía de fórmulas por lo que suponía «sobre la [pintura] de dichos impresionistas un avance considerable [...] Joaquín Sorolla es, hoy por hoy, el más grande, el más completo y el más fecundo de los pintores impresionistas [...] Pintar fue entonces sencillamente eso: pintar». Convertido Sorolla en el «caudillo» español del impresionismo «en su pleamar», reivindicaba para el pintor valenciano otro origen, en este caso hispánico, sumado al primero: «de normas clásicas, de normas perennes... Que asimila la honda y perdurable enseñanza de Velázquez»; pero poco debía Sorolla a los franceses si estos habían bebido de las enseñanzas de Velázquez y Goya, cavilaba. Concluía cargando contra la pintura moderna y sus críticos, a los que acusaba de incubar «el veneno de unas teorías estéticas deshumanizantes», en clara alusión al Ortega y Gasset de 1925 frente al arte «humanísimo» de Sorolla (De Pantorba, 1963a). Pantorba defendía la existencia de un impresionismo nacional enraizado en Velázquez, cuestión compleja que gravitaba sobre un nuevo concepto, el luminismo: una estrategia diferencial de cuño castizo que construía un ismo a la medida del valenciano ${ }^{5}$. 
Santiago Arbós, redactor jefe de Blanco y Negro, defendió que Sorolla era un «pintor tan popular como poco conocido» pues el tópico de sus pinturas de barcas ocultaba a un gran artista. Seguía la estela de opinión marcada por la modernidad canónica de que las periferias habían tenido un interés residual, presumiendo carencias en la pintura de Sorolla por no haber sido impresionista, es decir, por no haber participado de esta corriente específica de la pintura francesa, sino en lo que denominaba «impresionismo a la española», una corriente de escaso éxito debido a la tendencia hispánica al individualismo. Tirando de discurso biográfico, justificaba que el pintor no se quedara en París durante su estancia como pensionado porque era hombre familiar y decente cuyo carácter estaba reñido con el ambiente bohemio que reinaba en Montmartre. Subrayaba Arbós la modernidad de la obra «menor», apuntes y pequeñas pinturas pertenecientes a la colección familiar, expuestas por vez primera tras su muerte, y que sin duda resultaron sorprendentes: daban «la medida exacta de lo que hubiera sido Sorolla de haberse inclinado a la otra vertiente del impresionismo [el francés]», concluía (Arbós, 1963). Se trataba de la misma estrategia de legitimación de Pantorba, si bien Arbós conectaba a Sorolla con el paradigma de una modernidad que el historiador despreciaba. Idéntico objetivo tenía la publicación de los apuntes de Nueva York a tamaño natural en un reportaje que, con texto de Pantorba, dedicó también el Blanco y Negro a la exposición. Más allá de la sorpresa que generaba una obra diferente y poco conocida de Sorolla, se ponía en evidencia el fuerte parangón formal con la pintura impresionista. De nuevo Gaya Nuño con sus escuetas, precisas y agudas reflexiones revisa acertadamente la calificación de impresionista para Sorolla: «porque el impresionismo obliga a un método y a una disciplina mental, en tanto que nuestro gran valenciano fue siempre más obediente a su instinto de pintor, a su espontaneidad, sus felices improvisaciones» (Gaya Nuño, 1958: 93).

El aniversario fue clave en la rehabilitación de la figura de Sorolla desde la aquiescencia de la opinión pública, algo que reflejó la prensa, pero también caló en la historia del arte: una importante nómina de historiadores españoles como el marqués de Lozoya, Camón Aznar o Lafuente Ferrari le dedicaran ensayos. Aunque Sorolla había desaparecido de la historiografía internacional, su memoria se defendía en los textos españoles, si bien con una relevancia menor respecto a la que había saboreado durante las últimas décadas de su vida .

\section{La reinvención de Sorolla a partir de la democracia}

Habrá que esperar a los años 80 para que, al amparo de la posmodernidad, se dé el momento propicio para la rehabilitación de Sorolla. La suspensión de la modernidad canónica generó nuevas interpretaciones artísticas y contextuales de la pintura académica del XIX, o de algunas corrientes artísticas que habían sido escoradas durante décadas, como el naturalismo. En la escena académica esta relectura se plasmó en la publicación de 19th-Century Art de Rosenblum y Janson (1984), mientras que entre los museos la más relevante punta de lanza fue el Musée d'Orsay, que sacó de los almacenes la obra de aquellos pintores académicos e incluso pompier de gran éxito en su época, encerrados a cal y canto tras la entronización del modernismo de las vanguardias; un olvido que no siempre parecía justificado; historiadores europeos y norteamericanos especializados en el ochocientos vieron con alborozo que su objeto de investigación se resituara en la historia y el mercado. 
20 En España esta circunstancia coincidió con el lavado de cara de la cultura española en el exterior y con la descentralización del Estado, una política que cedía competencias hasta entonces exclusivas del Estado central a las distintas regiones. Respecto a la presencia de lo español en el extranjero, Bélgica acogerá en 1985 una de las primeras exposiciones sobre Sorolla en democracia (Vázquez de Parga: 1985). La muestra mantenía la lectura maniquea de la España Negra y la España luminosa al enfrentar, más que reunir, a Sorolla y Solana. El catálogo ilustraba que la fortuna crítica de Sorolla estaba experimentando un momento de cambio: Pierre Bertrand calificaba en la introducción a los dos pintores como «espagnols authentiquement d'Espagne», siguiendo la estela que defendía la pureza de raíz patria de la pintura naturalista, mientras sobrevolaba sobre esta afirmación un pintor no citado pero siempre presente, Picasso, al que desde los escenarios francófonos se ha considerado francés (Bertrand, 1985: 10). Resulta clarificador que se le encargara al escritor y articulista Francisco Umbral el ensayo principal de la publicación, manteniendo la práctica de que sobre Sorolla se generara teoría -y sobre todo opinión- desde la literatura más que desde la historia del arte. Es sorprendente que, en un encargo de este tipo, Umbral diera un zarpazo descomunal a Sorolla catalogándolo de «in-interesante» al afirmar «que Sorolla tenía mucho talento y muy mal gusto» (Umbral, 1986), añadiendo las ocurrencias literarias a las que era tan aficionado: «es un pintor brillante [...] pero poco atractivo». Lo calificaba de pintor costumbrista reaccionario carente de lecturas críticas: «buen burgués», «funcionario de la pintura», «retratista superficial», «Campoamor de la pintura» ${ }^{7}$. No podía salir peor parado el pintor valenciano.

21 La otra plataforma de visibilización de Sorolla se produjo como resultado de la España de las Autonomías. No sólo se descentralizó la gestión de la cultura, sino que se inició un proceso de valorización de autores locales combinado con reivindicaciones identitarias y discursos diferenciales; para cambiar el imaginario sobre el presente, había que mirar a las glorias pretéritas y transformar el relato canónico de la historia ${ }^{8}$. Sin duda Sorolla, cuya memoria en Valencia seguía viva, se convirtió en el paradigma del valenciano redimible. Resulta sintomático que se inaugurara en el año 1989 el IVAM, Instituto Valenciano de Arte Moderno, con una antológica de Sorolla que lo erigía como pintor moderno desde el Levante español. Pero la legitimación no culminó ya que después de esta muestra el rastro de Sorolla desapareció del nuevo museo iniciando sus colecciones con la figura del escultor catalán Julio González ${ }^{9}$.

Se evidenciaba la tensión intelectual que en estos momentos se producía entre la revisión del canon de la modernidad -con Tomás Llorens como uno de sus más firmes defensores- y los que deseaban mantenerlo inmutable-el equipo de jóvenes conservadores que a partir de ese momento llevaría las riendas del museo, con Carmen Alborch y Vicent Todolí a la cabeza ${ }^{10}$. Desterrar a Sorolla del IVAM estaba en clara sintonía con las decisiones adoptadas por otros museos españoles, como el MNCARS ${ }^{11}$. Sorolla, pese a haber protagonizado la apertura del IVAM, volvía a ofrecerse paradójicamente como una posible conclusión de la tradición al mantenerse su pintura en el museo de Bellas Artes de Valencia, una colección que arranca en el gótico y finaliza en el siglo xIx (González Baldoví, 1991).

La muestra de 1989 acreditaba que desde su ciudad natal se estaba orquestando una segunda rehabilitación en clave institucional del «gran mito cultural» valenciano, como lo definía la prensa. La colaboración con el museo de San Diego en Estados Unidos constataba la importancia de la aprobación de la sociedad norteamericana, la misma 
que lo había entronizado gracias a Huntington a principios de siglo xx. De hecho, antes de que la muestra recalara en el IVAM había pasado por San Luis, San Diego y Nueva York, donde la prensa destacaba que había recibido 150000 visitantes. Es de destacar que el comisario fue un marchante de arte impresionista, Edmund Peel ${ }^{12}$, por lo que se primaba el internacionalismo al tiempo que se ponían las cartas boca arriba respecto a las relaciones entre instituciones y mercado en un país, España, que por sus específicas circunstancias políticas tenía poca práctica al respecto.

Fue un paréntesis respecto a la modernidad canónica que el IVAM defendió en los años 90 , posicionándose a favor de una relectura de la pintura del siglo XIX que rescatara nombres orillados por la historia del arte, y que señalaba a Sorolla como el origen de ese cambio de paradigma. Maniobras expositivas similares se habían seguido, por ejemplo, con John Singer Sargent en Estados Unidos, muestra que de hecho Peel citó en la rueda de prensa para evidenciar que la rehabilitación de Sorolla no era un caso aislado (Beltrán, 1989). El comisario justificaba la exposición en el nuevo centro de arte moderno y contemporáneo con el débil argumento de que Sorolla pertenecía de manera natural a la época que le había tocado vivir, a diferencia de Pablo Picasso:

Sorolla fue en un principio un hombre de su época, según lo que la época pedía. Después rompió con el academicismo y desplegó su propia manera de pintar. Lo que ocurre es que coincidió con la aparición de un revolucionario llamado Picasso. Quizá Sorolla fue un hombre más de su tiempo que Picasso, que era un adelantado a su época (Beltrán, 1989).

Sustentar su argumento en una historia del arte que partía de la idea de progreso, y en Picasso como canon, no era la mejor estrategia para sacar a Sorolla de la tradición. Creemos que cuando afirma que Sorolla pintaba lo «que la época pedía» se refería implícitamente al mercado ya que resaltó las recientes ventas de sorollas y su inclusión en las colecciones valencianas para justificar la pertinencia de la muestra:
A la recuperación de su obra por las instituciones, iniciada por la Diputación de Valencia a finales de la década de los setenta con la adquisición de algunos de sus cuadros más conocidos, ha sucedido un creciente interés de los coleccionistas. Así, el pasado día 22, su obra Toros a enganchar la barca fue adquirida en Londres, en una subasta de Sotheby's, por la cantidad de 142 millones de pesetas. Al día siguiente, en Madrid, Edmund Peel \& Asociados, representantes de Sotheby's en España, vendía, entre otras obras, El remero por 80 millones de pesetas. (Beltrán, 1989)

Peel valorizaba la figura de Sorolla con dinero público y, en paralelo, le vendía los cuadros a las mismas instituciones que organizaban dichas muestras. Este conflicto de intereses es hoy cuando menos poco estético ${ }^{13}$. Pero entonces había en España escasa experiencia respecto a la organización de exposiciones, el mercado y normativas deontológicas hoy consensuadas.

La directora del museo, Carmen Alborch, mantenía su propia agenda: la exposición de Sorolla en el IVAM tenía componentes políticos, ideológicos y de reivindicación local, además de asegurar largas colas a la puerta del museo de un público que, de otra manera y como ella misma reconocía, «no (lo) habría visitado»; también realizó consideraciones de calado artístico al ser la muestra una oportunidad inmejorable «para deshacer el tópico reduccionista de este artista como pintor de las barcas y el mar» (Beltrán, 1989) ${ }^{14}$.

Tras esta muestra institucionalmente se apostó por la Casa Museo Sorolla, muy abandonada durante el periodo franquista: se difundieron colecciones con una programación continuada de exposiciones y se doto de conservadores. Además, se 
sucedieron en las siguientes décadas innumerables proyectos expositivos que releían la figura de Sorolla como: Sorolla-Zorn, (Madrid, Museo Sorolla, 1992), Sorolla (Madrid, Fundación Mapfre, 1995), Sorolla a Xàbia (Xàbia, 1998), Sorolla y la Hispanic Society (Valencia, Bancaja/Madrid, Thyssen-Bornemisza, 1999), Sargent/Sorolla (Madrid, Thyssen-Bornemisza, 2006), Sorolla y sus contemporáneos (itinerante por varias capitales españolas, 2008), Sorolla y la moda (Madrid, Thyssen-Bornemisza, 2018), etc. Esta inflación de exposiciones era aún más aguda en Valencia: entre 1998 y 2003 se organizaron ni más ni menos que diez en la capital del Turia dedicadas Sorolla (Bono, 2003). La más relevante según el número de visitantes trajo de vuelta temporalmente los paneles encargados por Huntington para la Hispanic Society y tuvo lugar en dos ocasiones en la Fundación Bancaja en 2007 y 2009 (Visión de España. Sorolla en las colecciones de la Hispanic Society of America y de Bancaja).

Fotografía de recorrido de Visión de España. Sorolla en las colecciones de la Hispanic Society of America y de Bancaja (Valencia, Fundación Bancaja, 2009).

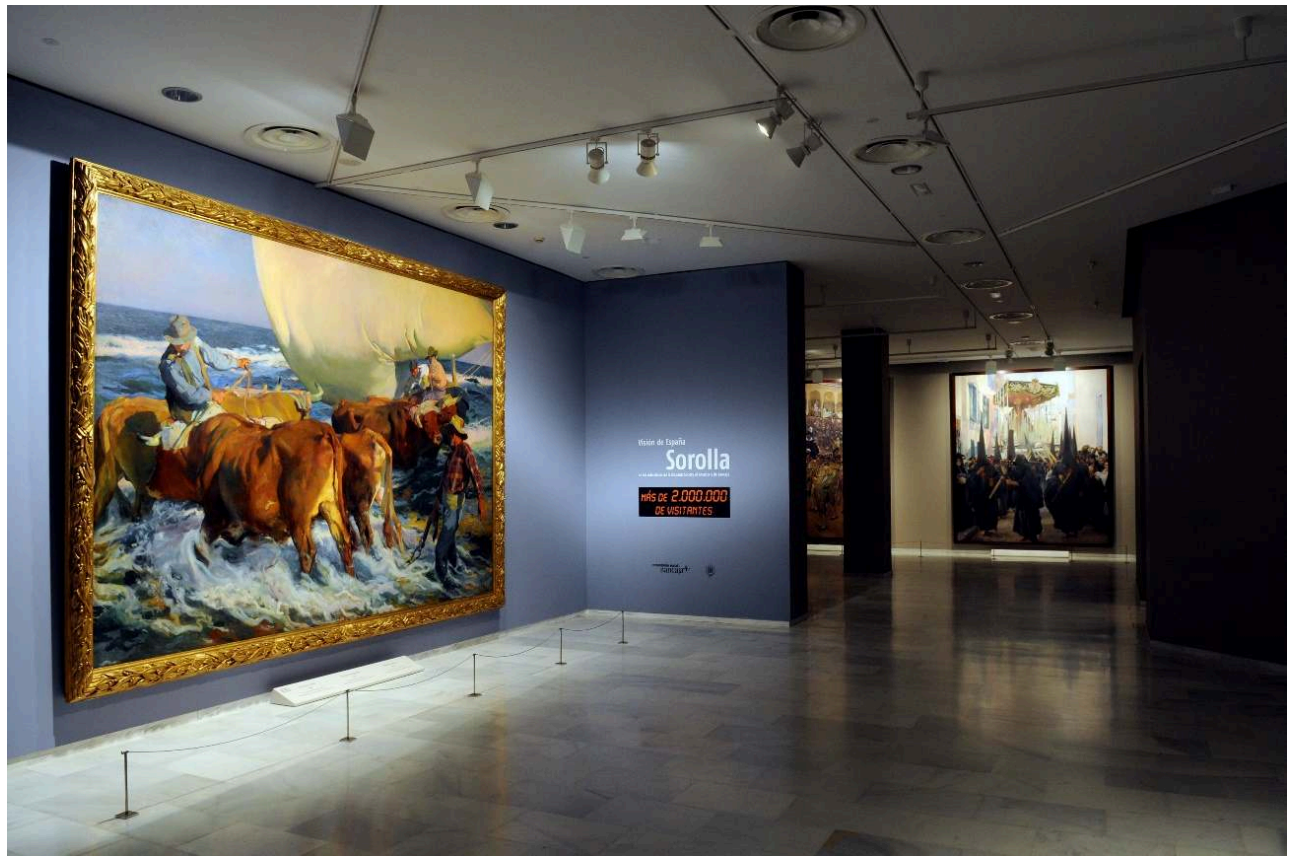

(C)Mantramuseografía. Paco López Foto.

Estos proyectos estaban en línea con las exposiciones que intentaban rehabilitar la maltrecha pintura del siglo xix español y que conectaban la tradición velazqueña en uno de sus cabos con la modernidad representada por Picasso atravesando la pintura del 800. Como hemos estudiado en otra ocasión, se trató de un proceso de redención y legitimación de la pintura decimonónica que tuvo en el Museo del Prado su mejor garante (Tejeda, 2016); su colofón consistió en integrar los fondos del 800 en las colecciones permanentes de un museo concebido como la encarnación de la mejor pintura española. Sorolla era uno de los grandes avales para esta regeneración de las colecciones del museo, no en vano la muestra Joaquín Sorolla (1863-1923) fue la más visitada de la década por encima de las de Tiziano o Tintoretto. De hecho se desmontó estratégicamente un mes antes de presentar sus colecciones del siglo XIX dentro de la colección permanente en 2009, en una pautada estrategia de legitimación que se plasmó en la Memoria de actividades: 
En la historia del Prado fue la primera vez que se abordó con esta amplitud una exposición de un artista del siglo XIX. En un periodo de revisión historiográfica de los principales movimientos de aquella centuria, esta muestra permitió advertir el interés y la originalidad de Sorolla, tanto en el ámbito español como en el internacional (Museo del Prado, 2009: 45). cuestión de si Sorolla era o no moderno. ¿Por qué la exposición tenía lugar en El Prado y no en el MNCARS? La tímida apuesta por la creación de un museo de arte moderno durante la dictadura cuajó en intentos como el MAC y el MEAC, sobre los que el Estado democrático decidió hacer tabula rasa y reinventarse (Lorente, 1998: 297). El Centro de Arte Reina Sofía se fundó en 1986 en un momento en el que un PSOE triunfante gobernaba en la práctica totalidad del país y el arranque de la modernidad en España se construía en paralelo al renacimiento democrático que experimentaba el país. Esta institución, convertida años después en museo, albergó las colecciones estatales y en 1995 se decidió que la fórmula a seguir para ordenarlas entre el Museo del Prado y el nuevo museo sería la fecha del nacimiento de Pablo Picasso. Aquellos autores nacidos antes de 1881 se concibieron como remate de la tradición, mientras que los nacidos a posteriori contaban con el prurito de seguir vigentes aunque llevaran décadas muertos. Picasso fijaba el canon, cuyos antecedentes no se hallaban en la pintura española del siglo XIX, sino en el arte africano, en la pintura románica, en El Greco, o en Cézanne. Se generó una lista de excepciones, de autores nacidos antes de 1881, que ayudaran a contextualizar la obra de Picasso en el MNCARS que ilustran el relato hegemónico en esos momentos. De esta manera, y habida cuenta de la inexistencia de relaciones entre la obra del malagueño y el valenciano, dicho relato condenaba a Sorolla a ser un artista en los márgenes de la modernidad; esto es, debía atesorarse en el Museo del Prado junto a otros compañeros de generación, como Aureliano de Beruete. Esta decisión daba soporte a una fuerte apuesta del gobierno en 1992: la salida de Picasso del Museo del Prado, personificada en su obra más emblemática, Guernica.

siguiente paso consistió en legitimar internacionalmente la figura de Sorolla. E evento expositivo más relevante en este sentido fue la antológica de la National Gallery de Londres en 2019, Sorolla: Spanish Master of Light, exposición que continuó su periplo en Irlanda. Este proyecto evidencia la importancia de las relaciones internacionales en la generación de exposiciones y en la re-escritura de la historia del arte y por su puesto su influencia en el mercado mismo; que el actual director del museo británico sea Gabriele Finaldi, profesional que fue adjunto a la dirección del Museo de El Prado, es fundamental en esta ecuación.

Sorolla, que había tenido en 1908 en Londres un éxito comercial relativo, era antes de la muestra del año pasado un absoluto desconocido para el público británico. Para el gobierno español este proyecto fue prioritario en su agenda: se apoyó por la AC/E, la agencia estatal promotora de la cultura española en el extranjero y fue inaugurado por la reina Letizia y el príncipe de Gales, una pareja mediática y de alto peso institucional. El museo calificaba en su web a Sorolla como de «impresionista español» y lo alineaba con parte de sus colecciones internacionales, si bien la selección de piezas tuvo un sesgo conservador que creemos quería conectar con el gran público apoyándose en sus cuadros más conocidos, muchos de los cuales habían sido difundidos desde las rehabilitaciones citadas del pintor desde los años 40 . Se perdió una gran oportunidad al prescindir de alguna de sus piezas más rompedoras y afortunadas, sus papeles $\mathrm{y}$ apuntes, lo que contrasta con los acentos puestos en su versión más tópica y 
regionalista, y a nuestro entender menos feliz: los paneles de Nueva York. Esta versión tópica, que redundaba en una versión de lo español que ni tan siquiera era fiel a la realidad a principios de siglo $\mathrm{xx}$, era celebrada en la tienda de regalos del museo, que siempre depara curiosas sorpresas sobre lo que se espera pueda consumir el espectador: en este caso packs para hacer sangría, cerámicas industriales de dudoso gusto y guitarras españolas de escasa calidad.

\section{BIBLIOGRAFÍA}

Ait Moreno Isaac (2010), Aportaciones a la historia del Museo Nacional Centro de Arte Reina Sofía 1979-1994 (Tesis doctoral), UCM, Madrid, <eprints.ucm.es/10858/1/T31873.pdf> (13/02/2011). AlVAREZ Junco José (2001), Mater dolorosa. La idea de España en el siglo xIX, Madrid: Taurus. ARBós BALLESTE Santiago (1963), «Joaquín Sorolla, en el Casón del Retiro», Blanco y Negro, 30/05/1963, 25 y ss.

BARoja Pío (2012), «Prólogo», E. Verhaeren, D. Regoyos (dir.), España Negra, Barcelona: José J. de Olañeta (original publicado en 1899).

BELTRÁn Adolf (1989), «Sorolla regresa a Valencia con una muestra antológica», El País, 02/12/1989.

Bertrand Pierre (1985), «Avant-propos», A. Vázquez de Parga (dir.) Sorolla/Solana, Lieja: Europalia 85 España, Salle Saint Georges.

BoNo Ferrán (2003), «Sorolla for ever», El País, 12/01/2003

CERECEDA Miguel (2010), «Emilio Varea, un intelectual de la República», R. Castells \& E. Lastres (dir.), Emilio Varela. Pintor universal 1887-1951, Alicante: Generalitat Valenciana, Ayto. de Alicante, CAM, 33-53.

CRARY Jonathan (2008), Las técnicas del observador. Visión y modernidad en el siglo XIX, Murcia: CENDEAC.

De BERUETE Aureliano (1901), «Joaquín Sorolla y Bastida», Revista Hispania (58), número extraordinario.

DE BERUETE Aureliano (1921), Joaquín Sorolla y Bastida, Madrid: Biblioteca Estrella.

De LA ENCINA Juan (1951), La pintura española, México DF: Fondo de Cultura Económica.

De PANTORBA Bernardino (1963a), «Estudio crítico», Sorolla 1863-1963, Madrid: Dirección General de Bellas Artes, sp.

DE PANTORBA Bernardino (1963b), «Sorolla, un gigante de la pintura moderna contemporánea», Blanco y Negro, 13/04/1963, 23 y ss.

GARCíA Manuel (2014), Memorias de postguerra. Diálogos con la cultura del exilio (1939-1975), Valencia: UV. 
GARÍN Felipe \& TOMÁs Facundo (2009), «La fortuna crítica de Joaquín Sorolla», J. L. Díez \& J. Barón (dir), Joaquín Sorolla (1863-1923), Madrid: Museo del Prado, Fundación Bancaja, 471-484.

GAYA NUÑo Juan Antonio (1958), Arte del siglo XX. Ars Hispaniae, Madrid: Plus Ultra.

GÉAL Pierre (1999), «L'invention de l'école espagnole de peinture aux XVIII ${ }^{\mathrm{e}}$ et XIX ${ }^{\mathrm{e}}$ siècles», Cahiers du GRIMH (1).

GonZÁLEZ BALDoví Mariano (1991), Guía de museos de la Comunidad Valenciana, Valencia: Generalitat Valenciana.

GuILBAUT Serge (2007), De cómo Nueva York robó la idea de arte moderno, Valencia, España: Macba.

HERNÁNDEZ Carmen (2014), El institucionismo en Sorolla. La representación de la Sierra de Guadarrama, Madrid: Museo Sorolla.

«Inaugurado el IVAM con una muestra de Pinazo» (1989), Diario Las Provincias,

<valenpedia.lasprovincias.es/historia-valencia/1989/

inaugurado_el_ivam_con_una_exposicion_de_pinazo>(01/12/2019).

IVARS José Francisco (1973), «En el cincuentenario de un supuesto impresionista. Por un Sorolla sin tópicos», Triunfo (550), 34 y ss.

JARQUE Fietta (1989), «La gran diferencia», El País, 23/11/1989.

LORENTE Jesús Pedro (1998), «Los nuevos museos de arte moderno y contemporáneo bajo el franquismo», Artigrama (13), 295-313.

«El museo Sorolla necesita la ampliación de sus instalaciones» (1980), ABC, 25/07/1980, 24.

KANTOR Sybil Gordon (2002), Alfred H. Barr, Jr and the Intellectual Origins of the Museum of Modern Art, Cambridge: MIT Press.

LADERO QUESADA Miguel Ángel (1996), «La "decadencia" española como argumento historiográfico», Hispania Sacra, 48(97), 5-50.

LLORENS Tomàs (2006), «Naturalismo y modernidad. Notas para un simposio», ensayo inédito entregado a los asistentes del simposio El naturalismo y la vida moderna, dirigido por Llorens en el Museo Thyssen-Bornemisza de Madrid (23-24/11/2006).

LLORENS Tomàs (2007), «Joaquín Sorolla. Una reflexión historiográfica», AAVV, Sorolla. Visión de España, Valencia: Fundación Bancaja, 105-107.

LLORENS Tomàs (2008), «Sorolla y el naturalismo en el entresiglo XIX-XX», J. Arnaldo (dir.), El naturalismo y la vida moderna, Madrid: Museo Thyssen-Bornemisza, 13-24.

LLORENS Tomàs (2016), «La modernidad de Sorolla», El País, 02/04/2016, <elpais.com/elpais/ 2016/03/21/opinion/1458563622_304513.html> (15/04/2020).

Museo del Prado (2009), Memoria de Actividades, Madrid: Museo del Prado.

Nicolàs Fúlvia (1985), «Los Sorolla de La Habana se exponen en la tierra del artista», El País, 31/01/1985.

NieTo Gratiniano (1963), S/T, Sorolla 1863-1963, Madrid: Dirección General de Bellas Artes, sp.

PÉREZ SEGURA Javier (1997), La sociedad de artistas ibéricos (1920-1936) [Tesis doctoral], UCM, Madrid, <eprints.ucm.es/2478/1/T22384.pdf> (05/03/2020).

PORTÚs Javier (2012), El concepto de pintura española. Historia de un problema, Madrid: Verbum. 
RoSENBLUM Robert \& JANSON H. W. (1984), 19th-Century Art, New York: Harry N, Abrams, Inc.

SIMó Trinidad (1989), «Acontecimiento», El País, 02/12/1989.

Sorolla/Solana (1985), A. Vázquez de Parga (dir.), Lieja: Europalia 85 España, Salle Saint Georges.

TEJEDA Isabel (2016), «El regreso del arte español del siglo XIX al Museo del Prado. Un ejercicio de retórica en dos asaltos y un preámbulo: Musée d'Orsay», Á. Molina (dir.), La Historia del Arte en España. Devenir, discursos y propuestas, Madrid: Polifemo, 447-508.

UMbral Francisco (1985), «Sorolla et Solana», A. Vázquez de Parga (dir.), Sorolla/Solana, Lieja: Europalia 85 España, Salle Saint Georges, 14-22.

UMBRAL Francisco (1986), «Sorolla», El País, 18/01/1986.

VEGA Jesusa (2018), «Franco, sus retratos y los años 40: revisitar el archivo visual», Hispanic Research Journal, 19(5), 513-536.

VVAA (1956), Un siglo de arte español (1856-1956), Madrid: Ministerio de Educación Nacional.

\section{NOTAS}

1. El país fue ocupado a principios de siglo, al tiempo que fue desangrándose territorialmente con la pérdida de todas sus colonias, las últimas, Filipinas y Cuba, en 1898.

2. Agradezco a la profesora Vega la lectura de este artículo y sus pertinentes consejos, que sin duda lo han mejorado

3. Juan de la Encina, seudónimo de Ricardo Gutiérrez Abascal, consideraba que la pintura de Sorolla dependía de una «emoción puramente visual de la realidad exterior, inmediata y popular». Para este crítico de arte su manera de hacer vibrar los colores resultaba estrepitosa (Garín \& Tomás, 2009: 473). En el último capítulo dedicado al «movimiento moderno» de su libro La pintura española, pasa de puntillas sobre el siglo XIX ya que «dentro de España no se produce ningún movimiento de valor extra-nacional», y obvia citar a Rosales, Fortuny o Sorolla, para saltar en su análisis de Goya a Picasso (1951: 206). Pese a que esta publicación es ya de los años 50, desde su exilio mexicano consideró que no tenía perspectiva suficiente para estudiar el caso del «movimiento moderno en España».

4. El sorollismo representado por los alumnos y seguidores de Sorolla se había convertido ya tras su defunción en una línea de fuerza de las exposiciones nacionales de Bellas Artes. Sólo en la de 1924 fueron seleccionados once de sus pupilos (Pérez Segura, 1997: 171).

5. El término fue acuñado en 1952 por Rafael Benet en su libro Impresionismo (Cereceda, 2010: 62).

6. En la exposición Un siglo de arte español (1856-1956) que organizó el Ministerio de Educación Nacional en 1956 con motivo del centenario de las Exposiciones Nacionales de BBAA, Sorolla estaba bien representado (18 pinturas y 11 apuntes) si lo comparamos con otros autores relevantes del XIX como Gisbert (3 obras), Regoyos (5), Federico de Madrazo (11), o Zuloaga, un pintor protegido por el régimen, con 9. Sólo era comparable la situación de Rosales con 23 piezas, o la de Pinazo con 34. Picasso, bestia negra del régimen, ni tan siquiera tenía representación, lo que ilustra los oídos sordos del régimen a la realidad del arte contemporáneo (VVAA, 1956). Publicado dos años después, el manual de Gaya Nuño en Ars Hispaniae está más en consonancia con el distinto éxito internacional que en ese momento tenían los pintores españoles: Picasso cuenta con 4 páginas y 11 imágenes reduciéndose la presencia de Sorolla justo a la mitad.

7. Campoamor fue un popular escritor español del siglo XIX que reivindicó el uso del lenguaje castizo y fue rechazado por la Generación del 98. 
8. El conseller de cultura, Ciprià Ciscar, en la rueda de prensa de la exposición Los sorollas de La Habana, hablaba en clave identitaria y refería cómo la pintura de Sorolla representaba una manera de sentir y de vivir valencianas (Nicolàs, 1985). Trinidad Simó, historiadora que realizó una importante monografía sobre Sorolla en esos años, se refería de similar manera coincidiendo con la exposición del IVAM: «algo hay en su impulso creativo en que, como colectivo, nos reconocemos», lo que conecta con la creencia en esencias grupales que comparte la gente de un determinado territorio (Simó, 1989).

9. El IVAM aceptó también la donación de la obra de Ignacio Pinazo por parte de su familia, pinturas expuestas en una muestra de gabinete como un conjunto cerrado. Se creaba de esta manera un marcado contraste entre los dos pintores: en Valencia Pinazo se ligaba a las colecciones de la modernidad y Sorolla, en el Museo de Bellas Artes, era el colofón de la tradición. 10. Fue Tomás Llorens, primer director del IVAM, quien decidió organizar la exposición, y no Carmen Alborch, que aunque inauguró la muestra no continuó el programa expositivo y de colecciones de su antecesor. Llorens, que había sido director General de Bellas Artes de la Generalitat Valenciana, ya había apoyado la organización de Los sorollas de La Habana en Madrid y Valencia (comisariada entre 1984-1985 por Felipe Garín, director Museo de Bellas Artes de Valencia). En el primer asalto en la construcción del pintor como un artista moderno y, por tanto, en el intento de dilatar el canon hacia otras gramáticas y geografías, Llorens iniciaba el camino de un dilatado análisis de la pintura de Sorolla que continúa a día de hoy; «Sorolla»-dijo«inicia la problemática de la modernidad en la pintura valenciana, muy distinta a la de la pintura internacional, y esto lo convierte en objeto de especial interés, porque puede contribuir a enriquecer los esquemas excesivamente difusos que circulan hoy en día sobre el concepto de modernidad» (Nicolàs, 1985). Esta exposición colocó en el mercado europeo cuadros procedentes de la isla caribeña, incluyendo dos del Museo Nacional de Bellas Artes de La Habana y que, presentes en la muestra, fueron subastados en Sotheby's: Toros a enganchar la barca y Playa de Valencia.

11. La primera propuesta de la colección permanente del MNCARS prescindía de la pintura académica de autores nacidos con posterioridad a 1881 (fecha del nacimiento de Picasso, autor que marcaba el punto de partida del museo) ya que, según declaraba su directora María Corral, «pertenecen a una tradición decimonónica» (Ait, 2010: 387).

12. Peel fue presidente de Sotheby's España fundando junto a José de Paz en 1998 Edmund Peel Fine Art Consulting Ltd. Según nos transmitió en entrevista telefónica Tomás Llorens (05/12/2019), conoció la pintura de Sorolla en su juventud durante la cual mantuvo relaciones de amistad con sus herederos.

13. Numerosos artículos en prensa citaban las ventas tanto en subastas nacionales como internacionales de la obra de Sorolla meses antes de la exposición del IVAM. En uno de ellos, Peel afirmaba: «Una exposición como ésta puede contribuir mucho a que haya una mayor demanda del pintor y suban los precios» (Jarque, 1989).

14. El periódico Las Provincias narraba así la inauguración: «El primer día en que se abrió la exposición al público, fue visitada por 8000 personas, cifra máxima teniendo en cuenta que los vigilantes del IVAM no dejaron entrar en las salas a más de 270 personas de una vez. Las colas para admirar la obra del valenciano universal fueron kilométricas durante todo el mes» (Anónimo, 1989). 


\section{RESÚMENES}

Los vaivenes sufridos por la fortuna crítica de la pintura de Joaquín Sorolla (Valencia, 1863 Cercedilla, 1923) en los últimos cien años partiendo de una primera exaltación, posterior deslegitimación, y actual rehabilitación será nuestro objeto de estudio: por un lado, el interés que su obra ha despertado en las últimas décadas aparejado a su instrumentación simbólica en clave identitaria; por otro, su reivindicación como eslabón de la historia del arte español en la propuesta de una modernidad alternativa, que cuestiona el canon vigente desde principios de siglo xx. Para ello nos serviremos de recursos que consideramos clave para entender este proceso de rehabilitación: las exposiciones dedicadas al pintor y su representación en museos y colecciones españolas.

This essay will dive into the fluctuations shown in the critical reception of Joaquín Sorolla (Valencia, 1863 - Cercedilla, 1923) in the last 100 years, which began in exaltation, continued with discredit, to end with his current restitution. On the one hand, our study will focus on the growing relevance attained by his work - intertwined with its symbolic use, instrumental in the making of national identities. On the other hand, we will underline his vindication as the missing link in the history of Spanish art, as a proposal for an alternate modernity: all of which questions the canon that has prevailed since the beginning of the $20^{\text {th }}$ century. For that purpose, we will employ resources commonly neglected in academia, but which we deem crucial to understand this process of reinstatement: the exhibitions of his oeuvre as well as his presence in Spanish museums and art collections.

\section{ÍNDICE}

Keywords: Sorolla, tradition and modernity, national identity, Spanish painting in the change of centuries, history of art exhibitions

Palabras claves: Sorolla, modernidad y tradición, identidad nacional, pintura española de entresiglos, historia de las exposiciones

\section{AUTOR}

\section{ISABEL TEJEDA MARTÍN}

Universidad de Murcia

istejeda@um.es 